\title{
El Enemigo: usos y actitudes de lo cristiano frente a lo moro
}

\author{
Juan Cañavate Toribio *
}

De las muchas hipótesis que se han propuesto para explicar la pervivencia de formas culturales islámicas en la sociedad cristiana posterior a la conquista del Reino de Granada, una de las más atrevidas y sugerentes es la que ofrecía, en el año 1986, Víctor Nieto Alcaide en un interesante artículo (NIETO ALCAIDE, 1986) en el que intentaba establecer algunos de los principios básicos que regulaban una compleja relación: la que se estableció, desde el punto de vista cultural, entre las sociedades islámica y cristiana en la baja edad media peninsular.

En el ámbito de la arquitectura y, sobre todo, en el marco temporal que se inicia tras la guerra de conquista del reino de Granada, el autor establecía algunas hipótesis de notable interés que explicaban la pervivencia de ejemplos de la arquitectura islámica en la sociedad que transitaba hacia el Renacimiento en la Península Ibérica.

La más significativa de estas hipótesis venía a identificar los restos de la arquitectura islámica en las ciudades cristianas, con lo que el autor llama "trofeos de guerra". Reconociendo al mismo tiempo la imposibilidad de definir, de forma precisa, las causas de las intervenciones urbanas cristianas posteriores y de sus condicionantes políticos, ideológicos o culturales.

"Entre el resultado, alteración figurativa de la ciudad medieval, y las razones que induje- ron a los mecenas a impulsar dichas construcciones, difícilmente podemos hallar conexiones en la mayor parte de los casos..." (NIETO ALCAIDE, 1986: p. 134)

Lo que el autor sí planteaba de forma clara, aunque no compartamos del todo su opinión, es que estas intervenciones se tradujeron exclusivamente en la construcción de edificios que pasaron a desempeñar una función simbólica sin alterar la trama urbana medieval.

"En el siglo XVI, ciudades como Toledo, Córdoba, Sevilla o Granada, cuya historia les confería una especial significación durante la dominación musulmana, no vieron alterado su trazado y su fisonomía medieval." (NIETO ALCAIDE, 1986: p. 134)

Se mantenían, por tanto, los trazados islámicos, además de algunos edificios que pudieran convertirse, por su valor simbólico, en un prestigiado "botín de guerra"; casos como la Alhambra de Granada, la Mezquita de Córdoba o la Giralda de Sevilla ocuparían así un espacio importante en esa galería urbana de botines.

Para evidenciar aun más la lógica humillación de los vencidos, se hacían necesarias, además, intervenciones en esos mismos edificios que dejasen clara la definición ideológica del nuevo poder dominador. Como resultado de

* Historiador 
ello nacerían el Palacio de Carlos $\vee$, en el recinto de la Alhambra o la catedral de Córdoba en medio de la vieja mezquita.

No podemos dejar de reconocer que la hipótesis que se plantea, desde el punto de vista de la historia política de la península, es enormemente seductora si lo que se busca es reforzar la idea del poder cristiano tardomedieval como algo intrínsecamente perverso en su relación con lo islámico. No nos encontraríamos simplemente ante un proceso de conquista política y militar, de todo punto lógico en la época, sino que además estaríamos ante algo nuevo para la Edad Media: un etnocidio cultural en el más estricto sentido del término.

Sin embargo, una afirmación de esta envergadura parte necesariamente de otra hipótesis que, aunque muy de moda en la actualidad, requeriría cuanto menos una revisión desde una historia que pretende analizar las contradicciones y no alimentarlas. Nos referimos a la existencia de una delimitación precisa entre las sociedades cristiana e islámica $y$, por supuesto, entre sus formulaciones culturales e ideológicas.

La vieja tradición historiográfica que mantiene viva la idea de una esencia romano-cristiana hispánica durante el accidental paréntesis islámico, volvería a salir reforzada aunque cambiando el papel de los actores.

Los cristianos romanizados de la nueva Castilla habrían mantenido durante los ochocientos años de presencia islámica su pureza de pensamiento y si conservan los viejos edificios islámicos es, simplemente, porque pueden actuar de "Triunfi" en rememoración de la tarea realizada, nunca porque considerasen que hubiese una cierta coincidencia entre sus planteamientos políticos y los discursos estéticos que dichos edificios soportaban.

Para que los supuestos anteriores se desarrollen, es evidente que se hace necesaria la existencia de una ruptura clara entre las dos sociedades en cuestión. Una hipótesis diferente no se entendería, desde estos presupuestos, sino como un ejercicio de diletantismo gratuito.
Pensar en la existencia de mutuas influencias entre una y otra invalidaría las tesis propuestas en cuanto que un proceso premeditado de aculturación por parte de los cristianos no puede ir dirigido contra aquellos mismos principios culturales de los que son copartícipes.

La posibilidad de que la arquitectura islámica, su uso o al menos los discursos formales de algunos de sus más ilustres ejemplos, fuese algo natural para un poder que no entiende la cultura mudejar como algo ajeno y que participa de gustos similares en muchos aspectos, no se suele contemplar en las investigaciones en materia de arte.

Todo lo más, se puede incidir en la maquiavélica capacidad de los Reyes para manipular esos discursos y así, Damián Bayón se permitirá afirmar:

"Al acercarse la unidad española, la intuición de asimilar también el arte mudéjar -o sea, el de los vencidos- representa un rasgo de genio" (BAYON, 199I: p. 5I)

Desde otra perspectiva, podríamos, sin embargo, llegar a preguntarnos si el mudéjar es realmente el arte de los vencidos o si el uso de la Alhambra como palacio real por parte de los Reyes Católicos, no es más que la consecuencia de algo simple: a los Reyes les gustaba y estaban habituados a esos modelos arquitectónicos y visuales. Supuesto que, por otra parte, ya había enunciado Torres Balbás en un preciado trabajo fechado en el año $195 \mid$ y titulado: el ambiente mudéjar en torno a la reina Isabel la Católica. (TORRES BALBÁS, 195।)

El primer paso, por tanto, para los que hegemonizan el proceso bélico, sería el de constatar la inexistencia o debilidad de la línea que separaría los dos lados. Para, a partir de ahí, dibujarla con trazo firme.

En ese caso la hipótesis de partida de Nieto Alcaide no sería demasiado útil y nos encontraríamos ante una ilustración más del enrevesado ideológico que suele acompañar a nuestra historia medieval y al complejo capítulo del final del Reino de Granada. 
En todo caso, el problema adquiriría algo más de nitidez si pudiéramos llegar a establecer, aunque nada más sea como mera sospecha 0 punto de partida, el grado de interdependencia, de mutua influencia que se establece entre las dos formaciones sociales que nos ocupan; la cristiana que evoluciona desde la fragmentación civil hacia un proceso de unificación y expansión territorial, pero que necesita para ese largo proceso avanzar en cohesión política o religiosa o cultural. Otra, la islámica que retrocede de forma imparable en cualquiera de sus formulaciones estructurales, pero que posee tal nivel de arraigo entre la población que difícilmente podrá eliminarse en su totalidad, aunque este objetivo estuviese en la mente de los reyes cristianos.

Aspectos como los hábitos alimenticios, el vestido, la estructura familiar, la arquitectura doméstica, la poesía, la filosofía o el arte, por nombrar algunos, constituyen ejemplos precisos de este proceso dialéctico compartido que, en una primera fase, se vive de una forma casi natural y sin que por ninguna de las partes (si es que durante el siglo VIII se puede hablar de la existencia de dos partes en conflicto) se explicite un análisis de las repercusiones que dicha mezcla pueda originar en el devenir de las nuevas sociedades que, inevitablemente, se irán creando.

También es cierto que lo islámico, en esa primera fase de su expansión en la península, se configura como una alternativa global que no encuentra grandes resistencias en los ámbitos ideológicos, culturales o políticos.

"A diferencia de lo que había sucedido con los visigodos, los musulmanes van a introducir en la vida peninsular cambios fundamentales, que se vieron favorecidos por la rápida conversión al islamismo y que influyeron incluso en los mismos reinos cristianos: Alfonso II de Aragón y Enrique IV de Castilla vestían a la usanza musulmana, Pedro I de Aragón firmaba sus documentos exclusivamente en árabe, etcétera..." (BOZAL, 1978: p. 54)

No vamos a entrar en el espinoso problema de la islamización de la península, nos con- formamos con constatar que el problema tiene distintas perspectivas y es algo más complejo que el mecánico funcionamiento de un proceso en el que de dos enemigos, uno vence, aniquila y elimina al otro.

De lo que no parece haber duda es que el enfrentamiento estallará $y$, por tanto, se hace necesaria la presencia de un "enemigo", al que el largo desarrollo del proceso va a permitir ir perfilando y definiendo, así como ir modificando aquellos factores que dibujan su imagen para adaptarla a las nuevas necesidades que surgen en los nuevos reinos en expansión.

Aunque aquí nos surjan dos preguntas que prácticamente tienen la misma respuesta. La primera es iqué hace diferente al enemigo? la segunda ipor qué es un enemigo? o expresado de otra forma ¿de quién es enemigo?

En principio a la primera pregunta, aunque tiene una respuesta lógica -es distinto porque es el enemigo-, le intentaremos dar respuesta a lo largo de estas páginas. A la segunda habría que responder que enemigos, en el sentido estricto, en la Edad Media peninsular, sólo los tiene la nobleza o quien participa de ella como la Iglesia, que comienza, así mismo desde muy pronto, a perfilar de forma concienzuda al enemigo; el infiel.

Aunque en una primera fase su lucha se desarrolle también en un ámbito casero, más adelante la definición del enemigo elaborada por la Iglesia se pone de forma indiscutible al servicio de los intereses de la experiencia monárquica de los Reyes Católicos y, sobre todo de los monarcas posteriores. Si olvidamos la confusión que genera la pervivencia del rito mozárabe, la Iglesia es quien más fácil lo va a tener: la línea que separa al Islam del cristianismo es más nítida que la que separa la forma de vida de un campesino castellano de uno granadino.

Un punto de partida sería el considerar el paso de lo islámico a lo no islámico como un proceso temporal en el que se va definiendo al enemigo a través de distintos perfiles que comienzan por respetarlo y combatirlo y que acaban por convertirlo en un sujeto despre- 
ciable que puede recibir distintos nombres, agareno, sarraceno, infiel o, simplemente, moro. Lo curioso es que ese proceso no se detiene con la caída de Granada, al contrario, se agudiza más adelante coincidiendo con la guerra de la Alpujarra y alcanza hasta prácticamente nuestros días.

“... a poco sobrevino la horrenda catástrofe de la invasión árabe." (GÓMEZ MORENO, 1889: p. 12)

Hemos manejado en el presente trabajo algunos documentos y, sobre todo, crónicas y libros de viajeros que se sitúan en los últimos años de ese proceso. Al margen de la dificultad para manejar material documental de fechas anteriores, lo cierto es que es en ese período cuando el esfuerzo es mayor por situar los límites entre los dos sectores enfrentados.

\section{El noble y el enemigo}

Así se tendrá que iniciar un proceso contra "el moro", en el que el primer paso será hacerlo diferente y se justificará, en principio, en el peligro que supone su presencia como militar, más tarde como infiel y más adelante será ya incluso su forma de vestir o de comer lo que le hace perverso y peligroso para la población cristiana.

El problema reside, como decía en el inicio, en que gran parte de esas actividades se han ido introduciendo en la forma de vida de la población cristiana que habita las ciudades o las tierras conquistadas y no solo entre los humildes habitantes de los campos

Ante una situación tan enormemente complicada para justificar una guerra que se desarrolla durante siglos, es necesario convertir al enemigo en un elemento potencialmente peligroso para toda la sociedad y no sólo para los estamentos nobiliares que se alimentan, viven y justifican su propia existencia en la guerra de frontera.

Pero la contradicción alcanza a todos los estamentos como iremos viendo y cuando decimos que en las ciudades conquistadas o capi- tuladas se seguían practicando costumbres islámicas, no debemos pensar solo en los mudéjares humildes. Tal vez sería más exacto pensar también en la nobleza o incluso en las altas cabezas de los monarcas como es notorio en los casos de Pedro I o Enrique IV.

Lo que sí aparece claro es que en las distintas actitudes que mantienen los cristianos frente al "otro" se aprecian factores derivados de la procedencia de clase de cada sujeto que la sustenta o de su inclusión en determinados segmentos del poder cristiano.

También y para complicar aun más el asunto, habría que añadir que las directrices dimanadas desde el poder real en cuanto al trato que debe recibir el enemigo, no siempre eran las mismas, dependiendo de la situación coyuntural en que se encuentran y contribuyendo a confundir aun más a la nobleza:

"Y como quiera quel dicho señor condestable oviera mayor placer de aver guerra con ellos que tener paz ni tregua, pero conoçiendo quel dicho señor rey avía dello placer, y se avía por seruido, reçibiole muy bien, y fizole muchas onrras" (CARRIAZO, 1940: p 203)

Hay multitud de ejemplos de instrucciones precisas de los reyes en referencia a este asunto, pero al margen de la existencia de normas en cuanto a la actitud y al trato, es notoria, en este fragmento de las crónicas del Condestable Iranzo, la distancia que separa al noble y al monarca en cuanto a su visión del enemigo. Teniendo en cuenta además que en este caso es un noble de probada fidelidad al rey.

En todo caso, lo único que nosotros y el rey podríamos reprochar al Condestable es el ser claramente coherente consigo mismo o con el estamento al que pertenece.

Esta diferencia de actitud no deriva de la mayor o menor simpatía personal que pueda provocar el deslumbrante mundo islámico de la corte granadina en el Condestable. Lo cierto es que un noble de la frontera que ha jurado fidelidad al rey y que además intenta obedecerle en su forma de tratar a unos futuros 
vasallos, debía sentirse como el escorpión que atraviesa el río sobre las espaldas de una rana y que, al hundirse con ella tras picarle, no puede dar más explicación que la de su propia naturaleza.

¿Qué cabría esperar de una nobleza que vive del pillaje, el saqueo, la extorsión permanente de un enemigo que es además la clave de su supervivencia como casta dominante en la frontera?

Rico en sugerencias es el siguiente fragmento en el que el autor de las crónicas deja clara la presencia del enemigo moro como el elemento clave que justifica no solo la necesidad de la caballería sino incluso la de la estructura trifuncional que sirve de sustento a la propia sociedad feudal.

". como cosa conocida era, segund que por los sabios antiguos estaba escrito, en todo el mundo ser tres estados: el primero de los oradores, el segundo de los defensores, el tercero de los labradores.....E que si esto, comúnmente, a todas las ciudades y villas y lugares convenía y pertenecía, muy mucho mas y con mayor nescesidad y evidente causa y razón a la dicha ciudad, por la grande vecindad y cercanía que con los moros, enemigos de nuestra santa fe, tenía. "(CARRIAZO, 1940: p 203)

La nobleza fronteriza necesita del enemigo y una primera imagen de ese confuso otro al que hay que diferenciar viene, como decía, definida por el marco en el que se sitúa el enfrentamiento, el campo de batalla. $Y$ aunque pueden encontrase algunas excepciones, en general nos encontramos frente a un guerrero valiente e, incluso feroz.

"... e llegaron los moros con las escalas hasta los muros e conbatían muy bravamente, osando morir..." (CARRIAZO, GOMEZ-MORENO, 1961: p | 17).

"E los moros salieron a defender que no se asentase el real, peleando muy ferozmente, como hombres muy esforzados....como aquellos que por lo suyo quería morir e defenderlo" (CARRIAZO, GOMEZ-MORENO, 1961: p. 180)
Esta apreciación tiene su lógica; afirmar que el enemigo es débil o cobarde, tampoco dejaría en buen lugar a quien se enfrenta a él.

Para un caballero cristiano es importante enfrentarse a un igual. Su valor se mide en ello y con ello se justifica en parte su modo de vida.

Pero de alguna forma tiene que dejar claro que el enemigo es "otro", que no se combate a aquel que por costumbre, religión o fidelidad vasallática es igual a sí mismo. Incluso cuando la guerra es abierta entre la misma nobleza castellana, se justifica haciendo referencia al "otro":

"E de cada día se facía muy más cruel guerra, e corrían las vegas e campiñas de Jahén quemando e talando los panes e las huertas, e robando todo el pan que en los cortijos y aldeas fallauan ensylado, prendiendo y matando los vecinos de Jahén, como si fueran moros, e con mayor crueldad. " (CARRIAZO, 1940: p 277).

El texto nos conduce a una realidad violenta y dura en la que el enemigo es considerado, sin contemplaciones, con toda la crudeza que se merece. Lo que el cronista no entiende es que la brutalidad de las tropas del marqués de Villena se ejecute contra cristianos, vecinos de Jaén. Podríamos deducir que no plantearía grandes inconvenientes si los masacrados o los autores de la masacre hubieran sido moros.

Esta imagen del enemigo sanguinario tiene un enorme éxito entre la nobleza y se podrá imponer al resto de la población a través de muchos medios, aunque es indudable que la Iglesia aportó lo suyo como nos demuestra el bachiller Bernaldez en sus memorias del reinado de los Reyes Católicos:

"Vengador quiere decir matador, el que mata sin piedad como hacían los moros antes de que el reino de Granada se sanasse; que sin ninguna piedad, cuando podían, matavan a los cristianos." (CARRIAZO, GÓMEZ-MORENO, 1961: p. 22).

La clave está en que hay una cierta justificación en la crueldad de la guerra cuando ésta va dirigida a un enemigo natural, a un moro 
que por una serie de razones es distinto, diferente, pero sobre todo, sanguinario.

La manipulación puede alcanzar altas cotas, sobre todo cuando la situación lo exige por lo delicado del proceso. Así se inician historias que se dejan correr de boca en boca en las que la crueldad del enemigo se hace cada vez mayor. Irán surgiendo en su compañía, además, historias de martirio que sacralizan espacios conquistados, como es el caso del Carmen de los mártires en la ladera sur de la Sabika o de simple violencia gratuita dirigida a inocentes como es el caso que señalamos a continuación.

"Y es muy posible que las gentes antiguas, mientras vivieron, se hubiesen mostrado firmes en la fe. $Y$ estos dos caballeros vieron la apariencia de ello; porque el día que allí llegaron fue cogido un niño pequeño, hijo de un cristiano, al que cortaron brazos y piernas y le arrancaron el corazón: y dicen que hacen a menudo cosas semejantes ..." (GARCÍA MERCADAL, 1952: pp. 475 y s.)

La reacción frente a este proceso, no será sin embargo homogénea; no toda la sociedad cristiana participa de una imagen del "otro" que lo identifica como enemigo. Incluso aunque eventualmente fuera el enemigo, esto tampoco le convertía exactamente en "otro". El hecho de ser enemigos no los convierte en diferentes. Una parte importante de esa sociedad ni siquiera lo considera como tal y otra, dejará de considerarlo así en el momento en que, por capitulación o conquista militar, el "otro" se convierte en súbdito de la corona o en vasallo de un señor cristiano.

"E cidihadiz e su hijo Muley Hacen, que anbos reinaron después, se vinieron huyendo en Castilla, al rey don Enrrique, con doszientos de cavallo o más; el cual los recevió y truxo consigo más de un año en la corte, e les fazía muchas onrras, e dava tanta suelta que las gentes murmuravan del rey, porque enojava a los cristianos por donde andavan." (CARRIAZO, GÓMEZ-MORENO, 1961: pp. 9,10)

Por ilustrar de alguna forma la diferente actitud mantenida por monarca y nobles frente al enemigo, quisiera señalar un último párrafo en el que la acción corresponde en este caso al enemigo. En concreto se refiere a los moros de Canbil y Alhabar cuando descubren que quien les asedia es el rey en persona y no un noble:

"Y como su alteza llegó, los moros salieron ; y entre los cristianos y ellos se trauaron algunas escaramuças. pero como los moros sopieron quel dicho señor rey estaua allí, enbiaronle suplicar y pedir por merçed les mandase dar su seguro para venir a le facer reuerencia. El qual seguro les otorgó. Y luego vinieron un fijo del alcayde de Canbil e otros moros con él, e le besaron las manos al rey; e troxieron mucha çeuada e pan e miel e quesos e pasas e almendras..." (CARRIAZO, 1940: p. 396)

Nos trae el texto un lejano sabor a caballería, a luchas entre nobles habituados a la guerra y que hacen de ella una forma casi natural de vida que no por violenta deja de tener sus refinadas normas de cortesía. Pero al parecer, el asunto no era siempre así. La guerra contra el infiel, contra el moro, no es ni mucho menos una actividad sometida al protocolo de una corte refinada en la que el rey aparece de vez en cuando.

Así nos la cuenta Jorge de Ehigen, caballero cruzado alemán que viene a Castilla a guerrear en el año 1457 y que nos muestra sin pudor el respeto que se tiene por el enemigo:

"Nos vimos, pues, en la necesidad de asaltar la mayor parte de las fortalezas y pueblos y dar muerte a todos los moros y a los asistentes y demás servidores. Tenían también orden de pasar a cuchillo a las mujeres y a los niños, como lo hicieron." (GARCÍA MERCADAL, 1952: p. 247)

\section{El gusto por lo moro}

Lo que nos llama la atención es que se tenga, al mismo tiempo, una cierta consideración y respeto a un enemigo al que así se trata en el campo de batalla.

Una de las causas, que no puede dejar de asombrarnos por otro lado, es la clara diferencia de objetivos y estrategias políticas que 
se manifiestan entre un rey como Enrique IV y cualquiera de sus sucesores $y$, como resultado de ello, sus diferentes actitudes respecto a lo "moro".

Sin embargo, con ser notoria la distancia que separa a estos, no deja de ser una nimiedad con la que separa a cualquiera de ellos con los monarcas europeos de la época.

Para estos o para sus representantes y embajadores, constituye una seria dificultad establecer los límites que separan a cristianos de musulmanes en las tierras ya conquistadas.

Torres Balbás resume y hace general la sensación normalmente desagradable que la convivencia pacífica con el supuesto enemigo en las cortes castellanas provoca en los visitantes extranjeros:

"Todos los extranjeros llegados a España en el S. XV y en los primeros años del XVI y que han dejado relación de sus viajes, desde el citado Tetzel en 1466 hasta el embajador veneciano Navajero en 1525-6 muestran un asombro que llega a veces hasta el escándalo, por el gran número de musulmanes que poblaban la España cristiana, extrañeza y condenación compartida por dos monarcas de otras tierras Felipe el hermoso y Francisco I de Francia" (TORRES BALBÁS, 195 I)

En 1466 estuvo en esa corte (la de Enrique IV) el barón bohemio León de Rosmithal, y su acompañante Gabriel Tetzel, patricio de Nuremberg, dejó, en su relato del viaje, un cuadro, tal vez excesivamente recargado, de la afición regia por los musulmanes. Describe a Enrique IV rodeado de moros, supeditado a ellos y por ellos dominado con perjuicios de los cristianos a muchos de los cuales había expulsado de la corte, y despojado de sus tierras en beneficio de los islamitas.

En la audiencia concedida en Segovia a Tetzel y a algunos de sus compañeros de viaje, el rey estaba "sentado en tierra sobre tapices, a la usanza morisca"; "come, bebe, se viste y ora -dice Tetzel- a la usanza morisca y es enemigo de los cristianos; quebranta los preceptos de la ley de gracia y lleva una vida de infiel" (FABIE, 1879)
Siguiendo a Torres Balbás, hemos acudido a informaciones más directas del viaje del noble bohemio, del que existen dos relaciones, una la del propio Tetzel y otra la del secretario del barón, Shaschek. De este último hemos seleccionado algunos fragmentos de interés.

En el primero de ellos, los viajeros pasan por Olmedo y así describe el secretario a sus habitantes:

"De esta ciudad no tengo que escribir otra cosa sino que sus habitantes son peores que los mismos paganos, porque cuando alzan en la misa el Cuerpo de Dios, ninguno dobla la rodilla sino se quedan de pie como animales brutos y hacen una vida tan impura y sodomita que me da pena y vergüenza contar sus maldades..... Viven entre ellos muchos paganos que llaman sarracenos; pero ¿quienes son mejores?: los cristianos o los sarracenos.? No juzgo fácil resolverlo." (GARCÍA MERCADAL, 1952: pp. 268 y s.)

La condena que establece Saschek es, en este caso, de índole moral. No nos cuenta que sus costumbres sean semejantes, solo que para él es indiscernible la calidad moral de unos y otros. De un párrafo así no podemos deducir que la mezcla de costumbres haga prácticamente iguales a unos y otros, pero por suerte, poseemos también el relato posterior de un noble polaco, Nicolas de Popielovo que visitó las cortes castellanas y aragonesas entre los años 1485 y 86 y que nos cuenta:

"...pero los habitantes de campo en Andalucía son aun mas groseros, que dificilmente se encontrarían en todo el mundo; y no hay de que extrañarse, porque viven con los brutos sarracenos, se relacionan y comercian con ellos, respiran su aire pagano, salvaje y rudo, y en muchas cosas siguen sus costumbres.". (GARCÍA MERCADAL, 1952: p. 322)

“...porque en todas las tierras de Andalucía, Portugal y Algarbía, los edificios y los hombres se asemejan, y la diferencia en la educación, costumbres y porte entre los sarracenos y los cristianos únicamente se puede apercibir en la religión; sin embargo, los cristianos practican muy mal su fe." (GARCÍA MERCADAL, 1952: p. 307) 
La lejana procedencia de los viajeros nos da alguna pista sobre el tamaño de su estupor; por mucha herencia visigoda que se reivindique para los reyes castellanos o aragoneses del final de la Edad Media, en el fondo seguían perteneciendo a un horizonte cultural -el Mediterráneo- que, si había sufrido grandes movimientos en su desarrollo, jamás, ni siquiera con el Islam, se había fracturado.

Desde ese horizonte compartido, era mayor la distancia que separaba a Enrique IV de las cortes de Polonia o de Bohemia, que de las de Túnez o Nápoles.

Sin embargo, la posición ideológica y cultural de las cortes europeas será la que acabe imponiéndose en las castellanas, de forma apenas esbozada con Felipe el Hermoso y definitivamente con Carlos V.

Sin embargo, será en tiempos de Enrique IV cuando el problema empieza a hacerse evidente. Ya en la crónica de Alfonso de Palencia se manifiesta de forma precisa la preocupación que el monarca genera entre la nobleza cuando se trata de los moros "cuyo séquito aumentó, alcanzando sus trajes tal aceptación, que a Enrique IV era más grato el que mejor los imitaba." (PAZ Y MELIÁ, 1940)

De hecho el asunto debió alcanzar tal envergadura y sus efectos tan nocivos para la imagen del monarca entre sus nobles que el príncipe D. Alfonso no deja pasar la oportunidad de utilizar el mismo argumento para justificar sus pretensiones a la corona:

"...el rey ha sostenido a los moros enemigos de la fe católica, trayéndolos consigo, hospedándolos en su palacio y dotándolos con doble sueldo que a los cristianos" (SERRANO, 1943:p. 84)

Dicho de otra forma, para Felipe el hermoso y para Francisco I los nuevos españoles no se diferenciaban gran cosa de los viejos moros.

Si siguiéramos ciertas corrientes historiográicas, la reacción inmediata sería pensar en una corte depravada como la que denuncia el príncipe D. Alfonso y otros.
Pero para colmo, el mal no era sólo un capricho del monarca y no era éste al único que le costaba desprenderse de sus maneras moras.

“...recluidas las mujeres de las clases acomodadas dentro de las casas andaluzas, sentábanse, como las moras, en el suelo y fisgoneaban la calle tras las celosías de ventanas y ajimeces." (TORRES BALBÁS, 195।: p.87)

A partir de un momento dado, coincidiendo con el aumento en importancia y relativa estabilidad de los reinos cristianos, la influencia mutua y notoria comienza a convertirse en motivo de reflexión y preocupación para un sector dominante en las estructuras de poder de los nuevos reinos que basan gran parte de su estrategia en su capacidad de hegemonizar el proceso histórico no solo desde el éxito militar.

En el fondo no podían olvidar que por muy agradables, seductores o cultos que fueran los gustos y costumbres en los reinos musulmanes, estos seguían siendo enemigos y no dejaba de ser inquietante la infiltración de sus formas de vida en los nuevos modelos cristianos.

Dicho de otra forma; incluso aquellos que intentaban acabar con ochocientos años de tradición islámica, se sentían tan islamizados que comenzaba a preocuparles si esto sería compatible con sus planes para el futuro.

\section{El uso de las ropas}

En la baja edad media, el uso de las vestimentas moriscas por parte de los cristianos atiende en general a tres razones. Una de ellas forma parte de necesidades militares, la segunda corresponde a una exhibición de lujo por parte de la nobleza y la tercera es el resultado simple de la costumbre.

Al hablar de necesidades militares nos estamos refiriendo a una especie de guerra psicológica, representaciones de carácter militar que se traducen en fingidas batallas entre moros y cristianos o desfiles cargados de parafernalia bélica en la que la presencia del enemigo es 
inevitable así como la necesidad de vestirlo de forma adecuada para la representación.

"... tocados a la morisca, y con barbas postizas..., desçendieron de allí fasta treynta onbres, vestidos y calçados como moros, con panderos y sonajas..., E luego más adelante salieron fasta quatro mill niños en cauallejos de caña, todos con alcandoras vestidos y tocados con tocas." (CARRIAZO, 1940: p. 195)

En la siguiente escena que se refiere, la fingida batalla se desarrolla con motivo de las fiestas organizadas para celebrar el nacimiento de la primera hija del Condestable.

"Y des que vino la noche, el comendador de Montizón, hermano del dicho señor, del un cabo, con fasta doscientos caualleros cristianos, y de la otra parte el asistente Fernando de Villafañe, con otros doscientos caualleros moriscos, con baruas postiças, y tiznados, con muchas tronpetas..." (CARRIAZO, 1940: p.259)

Como hemos podido comprobar las vestimentas moras son un requisito imprescindible para las fiestas en las que el juego de cañas y los torneos de todo tipo, son habituales.

Menos habitual y algo más sorprendente es lo que nos cuenta acerca de estas fiestas un viajero extranjero al que ya conocemos; Antonio de Lalaing que en el año I50 I llega a España acompañando a Felipe el Hermoso. Al parecer, estas fiestas no eran patrimonio exclusivo de la nobleza castellana.

“....Un poco antes, en una plaza llamada la Realeza, donde el rey moro hacía las corridas de toros y los juegos de cañas, hay una casa de piedra sumamente propicia desde donde las damas contemplaban esas luchas." (GARCÍA MERCADAL, 1952: p. 475)

¿Quiere decir que los moros también hacían corridas de toros y que la fiesta nacional por antonomasia era también compartida por ese enemigo supuestamente distinto?

Dejaremos por el momento la pregunta en el aire y volveremos a las fiestas organizadas por el Condestable recordando que el enemigo va vestido a la morisca y su aspecto es oscuro para lo que se tizna la cara y lleva barba postiza.

En la situación de tensión bélica que vive la frontera es lógico el referente del enemigo secular, pero lo más curioso es que éste no aparece nunca ridiculizado ni sujeto a burla. Las formación y desfile de las batallas son una parte importante de los ejercicios militares y el enemigo sobre todo, debe ser un valiente, un igual al que se le crítica con aspereza cuando elude el combate.

El problema se puede complicar algo más cuando descubrimos que el recurso a la vestimenta del enemigo, no solo se utiliza para representarlo sino también para imitarlo. Es cuando la situación exige un acto de máxima ostentación del poder del Condestable que no duda en usar las ropas en un referente del lujo y la sofisticación que caracteriza al poder islámico, desarrollando un principio de emulación con sus enemigos.

De las mismas crónicas hemos sacado algunos ejemplos.

"...vestido un sayo de chamelote azul, de muchos espesos tenblantes de oro sembrado, y al cueIlo una muy gruesa cadena de oro, una azagaya en la mano y el adarga enbraçada, un capirote morisco de muy fina granda tocado.

En pos dél yvan dos pajes de hedad de catorce o quinze años, muy moriscos, en sendos cavallos de la gineta, con muy ricos jaeces. Detrás destos yvan fasta treynta o treynta y cinco de los criados continuos de su casa, a cavallo, bien ajahezados, vestidos y tocados a la morisca.." (CARRIAZO, 1940: p. I38)

Considerando incluso la respetable obligación del cronista de servir a su señor, no deja de sernos de utilidad otra descripción del Condestable:

"...fasta quel dicho señor Condestable se leuantaua y caulgaua, media hora antes que amanesciese; muy gentilmente vestido y tocado a la morisca..." (CARRIAZO, 1940: p. 17I) 
Para rematar en la siguiente que sitúa al señor en el máximo nivel del bienestar:

"Y luego después que dicho señor Condestable ovo comido, el cual no sabía que se facer de placer, caualgó a la gineta, con una aljuba morisca de seda de muchos colores." (CARRIAZO, 1940: p. 258)

Como vemos, a este noble caballero castellano, no le pasaba desapercibido que la mejor manera de manifestar el más refinado lujo que por su condición se merecía, era imitando en sus gustos al enemigo.

También es cierto que por la excesiva proximidad de la frontera, las costumbres pudiesen alterarse hasta el extremo de que los nobles se dejasen arrastrar por un cierto snobismo en el vestir, pero también aquí nos saca de dudas Lalaing. En su viaje, visita Toledo y quisiera hacer notar que ya no estamos ni cerca de la frontera ni bajo la "malévola influencia" del controvertido Enrique IV.

"El viernes, dia de la natividad de San Juan Bautista, el rey y el archiduque, acompañados de varios grandes señores y caballeros, encontraronse desde muy temprano a un cuarto de legua fuera de Toledo. El archiduque y el almirante, y los caballerizos mayores del rey y de monseñor, iban vestidos a la morisca, muy lujosamente. Llevaban albornoces de terciopelo carmesí y de terciopelo azul, todos bordados a la morisca. La parte baja de sus mangas era de seda carmesí, y además de eso grandes cimitarras, y tambien capas rojas, y sobre sus cabezas llevaban turbantes. " (GARCÍA MERCADAL, 1952: p. 465)

Otra cuestión que nos contestan las crónicas es saber hasta dónde llegaban estos gustos por los ropajes moriscos. iSe quedaban simplemente en la nobleza o también los monarcas participaban del gusto a lo moro?

Ya hemos visto como en los casos de Pedro I y de Enrique IV las cosas estaban claras, pero ¿le ocurría lo mismo a la reina y al rey?

El cura de los Palacios, un personaje al servicio de la corona especialmente agresivo con lo "moro" nos da algunas pistas en el capítulo dedicado a la toma de Illora y Moclín:

"Venía la reina en una mula castaña, en una silla de andas guarnecidas de plata dorada; traía un paño carmesí de pelo, e las falsas riendas e cabeçada de la mula eran rasas, labradas de seda, de letras de oro entretalladas, e las orladuras bordadas de oro; e traía un brial de terciopelo, e debaxo unas faldetas de brocado e un capuz de grana vestido guarnecido, morisco, e un sonbrero negro... El rey tenía vestido un jubón de clemesín de pelo, con quixote de seda rasa amarillo; encima un sayo de brocado e unas corazas de brocado vestidas, e una espada morisca ceñida, muy rica,..." (CARRIAZO, GÓMEZMORENO, 1961: p. 170).

Como podemos ver la costumbre no se limitaba a la nobleza. También la monarquía utilizaba esa referencia al lujo moro que, en un superficial análisis confirmaría lo que defendía Nieto Alcaide: la espada morisca como trofeo de guerra que el rey luce en la entrada de las ciudades conquistadas.

Sin embargo, la cosa no es tan sencilla; el viejo Tendilla, ardiente defensor de los preceptos de la monarquía feudal que representan los reyes, manifiesta en más de una ocasión su respeto hacia las viejas costumbres de los nuevos vasallos. Hombre ilustrado como era y buen conocedor de las nuevos aires humanistas que llegan desde Italia, utiliza un sorprendente argumento para defender su causa y escribe al rey:

"...que aquí se ha dicho públicamente y escrito de su corte, que su alteza a mandado dar provisiones para que ninguna mujer nuevamente convertida traiga abito morisco" (MENESES GARCÍA, 1973: p. 553)

Más adelante sigue:

"Una cosa se puede decir en favor destos a los que dizen que no es abito de cristianos, que las romanas traen oy el abito que traian cuando eran gentiles, mas de dozientos años antes del avenimiento de nuestro señor..." (MENESES GARCÍA, 1973-4: p 558) 
Al margen de lo inusual del argumento que casi convierte al viejo conde en un maestro neoplatónico, lo que parece claro es que, conocedor como nadie de los problemas que se generan entre la población del nuevo reino, no le parece nada bien que las cosas avancen por esa vía y la pregunta no puede ser más senciIla: si las romanas la usan y no se pone en su duda su cristianismo, ipor qué no han de usarla las granadinas? Estaba más o menos claro que el problema era otro.

Es también evidente que la revuelta del Albayzín, apenas unos meses más tarde, cambiaría de forma radical el estado de las cosas y las acciones políticas de la monarquía frente a los enemigos vencidos. Pero esas actuaciones no tenían porqué cambiar necesariamente la imagen que los reyes tenían de sus nuevos súbditos. De hecho es también ilustrativa la carta que el rey Fernando manda al Conde de Tendilla tras los sucesos del Albayzín:

"...porque del arzobispo de Toledo que nunca vio moro, ni los conoció, no me maravillo, pero de vos y del corregidor, que tanto tiempo ha que los conocéis, de no haverlo dicho, y más que divulgose. Emos por bien de buscar manera para que quieran no faltar así a estas cosas, aunque no puede ser mayor que decir que los tornan cristianos, por no ser bueno...y no hagais culpantes a más de los matadores del alguazil, y estos con todas las maneras buenas...y estos tales casos mas son para que se siga el seso, que no la rigor.." (MENESES GARCÍA, 19734: p. 63)

Hay numerosos ejemplos de estas actitud de los monarcas para con sus nuevos súbditos pero no es el objeto de este trabajo el analizar las relaciones de los monarcas con la población mudejar, por lo que concluiré este pequeño apartado dedicado a la vestimenta con la transcripción de un fragmento de una provisión firmada por la reina Juana en 1513 que mantiene una actitud muy similar a la de su efímero consorte Felipe: "....ninguna cristiana vieja no pueda bestir ny bista a la morisca ny traiga almalafa so pena de que por la primera vez que pasare pierda los bestidos e le sean dados a otra y por la segunda vez que sea desterrada de todo el reino de Granada...." ।

El texto no deja lugar a dudas; en los primeros años del siglo XVl, la población sigue vistiendo con los ropajes moriscos y ésto se convierte en un autentico problema de orden público que se castiga incluso con el destierro. Lo más significativo es que no estamos ni nosotros ni la reina hablando de las costumbres de cristianas nuevas, que había sido el motivo de las cartas de queja de Tendilla. Se explicita claramente que son cristianas viejas, libres de toda duda respecto a su pasado de sangre a las que se prohibe que vistan a la morisca para evitar el mal ejemplo que les dan a las nuevas.

Al parecer $y$, tras los muchos esfuerzos realizados, sigue siendo difícil distinguir en sus costumbres a un cristiano viejo de uno nuevo. Pero no porque el nuevo imite al viejo, sino al revés, o dicho de otra forma, porque el cristiano viejo sigue practicando las mismas costumbres que tenía cuando los límites entre unos y otros no existían.

Aunque conviene señalar algo que decía al principio de este documento; la modificación de los factores que definen al enemigo que comienza a identificarse ya, no por su poder militar, ni siquiera por cuestiones de orden religioso. Son sus costumbres las que lo hacen peligroso y por tanto le convierten en enemigo.

Es ya una escalada de animosidad que con el tiempo se irá haciendo cada vez mayor y en la que todo vale para descalificar a aquellos que hay que hacer distintos en todo, sea en su vestimenta, en sus costumbres, en sus usos y no solo en la religión.

El cura de los Palacios es especialmente contundente en ésto y llega incluso a transmi-

| Archivo municipal de Granada, sección fomento, legajo 1929, pieza |.La traducción es del autor. 
tirnos algo tan especial como la propia forma de ser de los moros

"E como los moros son voltarios e muy livianos en sus fechos..." (CARRIAZO, GÓMEZ-MORENO, 1961: p. 177)

Al parecer su capacidad de definir al enemigo avanza de forma implacable conforme va desarrollándose la campaña y ya, a pocos días de la entrega de la ciudad de Granada, escribe:

"E los dichos rehenes entregados, como los moros sean movibles e muy livianos en sus movimientos e alborotos e agüeros, creyeron muchos dellos a un moro que se levantó por la cibdad diziendo desvarios: que avian de vencer ellos, e ensalçando al perro de Mohamad e rebtando el partido." (CARRIAZO, GÓMEZ MORENO, 1961: p. 230) ${ }^{2}$

No es ni mucho menos el cura de los Palacios el único que se atreve a describirnos la forma de ser y las costumbres de los musulmanes granadinos. El mismo Saschek se atreve en su relación del viaje a darnos algunos datos significativos:

"las costumbres de los sarracenos granadinos son estas: cada uno tiene siete mujeres, y si no le place alguna, la puede repudiar y casarse con otra; entre ellos vimos muchos judíos con quienes viven en paz; si no están contentos con su rey le destronan o le matan y ponne otro lo cual hacen con frecuencia; en aquel pais son las mujeres muy hermosas y bien ataviadas, pero los hombres son muy feos. La tierra es muy buena $y$ abundante en frutos. Tiene mezquitas muy bellas, según su gusto, y muy limpias" (GARCíA MERCADAL, 1952: p. 288)

\section{FUENTES Y BIBLIOGRAFIA}

BAYÓN, D. (1991). Mecenazgo y arquitectura en el dominio Castellano (I 475-I 62 I). Granada.

BOZAL, V. (1978). Historia del arte en España. Madrid.

CARRIAZO, J. de Mata. (1940). Hechos del Condestable don Miguel Lucas de Iranzo. Madrid.

CARRIAZO, J. de Mata, GÓMEZ-MORENO, M. (196I) (Eds.) Memorias del reinado de los Reyes Católicos que escribía el bachiller Andrés Bernaldez, Cura de los Palacios. Madrid.

FABIE, A. M. (1879) (Traducción, introducción y notas). Viajes por España de Jorge de Einghen, del barón León de Rosmithal de Blatna, de Francisco Guicciardini y de Andrés Navajero. Madrid.

GARCÍA MERCADAL, J (1952)(Recopilación, tradución y notas) Viajes de extranjeros por España y Portugal desde los tiempos más remotos hasta finales del siglo XVI. Madrid.

GÓMEZ MORENO, M. (I889). Ultima edición 1994. Guía de Granada. Granada.

MENESES GARCÍA, E. (1973) Correspondencia del Conde de Tendilla. Madrid.

NIETO ALCAIDE, V. (1986) "El mito de la arquitectura árabe, lo imaginario y el sueño de la ciudad clásica", Fragmentos revista de arte, números 8 y 9 . Ministerio de cultura.

PAZ Y MELIA, D.A. (1940) (traducción). Crónica de Enrique IV, escrita en latín por Alfonso de Palencia. Madrid.

SERRANO, L. (1943) Carta del príncipe D. Alfonso al concejo de Burgos, leida en sesión municipal de 17 de agosto de 1465. Citada en: Los Reyes Católicos y la ciudad de Burgos. Madrid.

TORRES BALBÁS, L. (195I) "El ambiente mudejar en torno a la reina católica y el arte hispano musulmán en España y berbería durante su reinado". Curso de conferencias sobre la política africana de los Reyes Católicos. Madrid.

2 El texto se refiere a la huida de Mohamed, hermano de Abdul Hacen e hijo de Çidi Çaha de la ciudad de Granada con ochenta caballeros que se unen al Condestable. 


\section{RESUMEN:}

Entre lo islámico y lo cristiano, la sociedad medieval que habita la península ibérica vive un mundo de contradicciones aparentemente insalvables.

En realidad esa sociedad rica y variada en lo cultural y en lo religioso, asumirá la mezcla de una forma natural y no traumática hasta que las estructuras políticas de los nuevos reinos cristianos se vean en la necesidad de imponer un horizonte cultural unificado para toda la población.

\section{PALABRAS CLAVES:}

Granada, Reyes Católicos, Islámico, Nazarí.

\section{ABSTRACT:}

Between the Islamic and the Christian worlds, the mediaeval society inhabiting the Iberic Peninsula is caught in an apparently unsolvable world of contradictions.

Actually, this culturally and religiously rich society, will assume this mixture as something natural, in no traumatic way, at least until the political structures of the new Christian kingdoms be forced to impose a unified cultural horizon upon all the population.

\section{KEYWORDS:}

Granada, Catholic Kings, Islamic, Nasrid. 